\title{
Noninvasive follicular thyroid neoplasm with papillary-like nuclear features: a problematic entity
}

\author{
Klaudia Zajkowska ${ }^{1}$, Janusz Kopczyński ${ }^{2}$, Stanisław Góźdź ${ }^{3}$ and Aldona Kowalska ${ }^{1,3}$ \\ ${ }^{1}$ Endocrinology, Holycross Cancer Centre, Kielce, Poland \\ ${ }^{2}$ Surgical Pathology, Holycross Cancer Centre, Kielce, Poland \\ ${ }^{3}$ Faculty of Health Sciences, Jan Kochanowski University, Kielce, Poland
}

Correspondence should be addressed to K Zajkowska: klaudia.ziemianska@gmail.com

\begin{abstract}
Noninvasive follicular thyroid neoplasm with papillary-like nuclear features (NIFTP) is a borderline thyroid tumour formerly known as noninvasive encapsulated follicular variant of papillary thyroid carcinoma. The prevalence of NIFTP is estimated at $4.4-9.1 \%$ of all papillary thyroid carcinomas worldwide; however, the rate of occurrence of NIFTP is eight times lower in Asian countries than in Western Europe and America. At the molecular level, NIFTP is characterised by the lack of BRAF V600E and BRAF V600E-like mutations or other high-risk mutations (TERT, TP53) and a high rate of RAS mutations, which is similar to other follicular-pattern thyroid tumours. The diagnosis of NIFTP can only be made after histological examination of the entire tumour removed during surgery and is based on strictly defined inclusion and exclusion criteria. Although the diagnosis is postoperative, the combination of certain findings of preoperative tests including ultrasonography, cytology, and molecular testing may raise suspicion of NIFTP. These tumours can be effectively treated by lobectomy, although total thyroidectomy remains an option for some patients. Radioactive iodine and thyroid stimulating hormone suppression therapy are not required. NIFTP has an extremely good prognosis, even when treated conservatively with lobectomy alone. Nevertheless, it cannot be considered as a benign lesion. The risk of adverse outcomes, including lymph node and distant metastases, is low but not negligible.
\end{abstract}

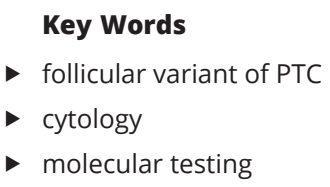

Endocrine Connections (2020) 9, R47-R58

\section{Introduction}

The follicular variant of papillary thyroid carcinoma (FVPTC) is the second most common histological variant of papillary thyroid carcinoma (PTC) (1). There are two variants of FVPTC, non-encapsulated (infiltrative) and encapsulated. The encapsulated variant of FVPTC (EFVPTC) may exhibit features of vascular or capsular invasion (Fig. 1). Individual forms of FVPTC differ in molecular profile, clinical behaviour and prognosis $(2,3)$. Evidence suggests that among different variants of FVPTC, noninvasive EFVPTC has an extremely indolent clinical behaviour and good prognosis. In 2016, an international group of endocrine pathology experts led by Nikiforov conducted a retrospective study that included 109 patients with noninvasive EFVPTC (67 patients underwent lobectomy, and none of them received radioactive iodine ablation) with a follow-up of 10-26 years and 101 patients with invasive EFVPTC observed for 1-18 years (4). In the group of patients with noninvasive EFVPTC, none died as a result of the disease, and no patients developed metastases or structural or biochemical recurrence during the follow-up period. By contrast, in the group of patients with invasive EFVPTC, adverse events were reported in 12 (12\%) cases (five patients developed distant metastases to the lungs or bones, two died from the disease, one had lymph 


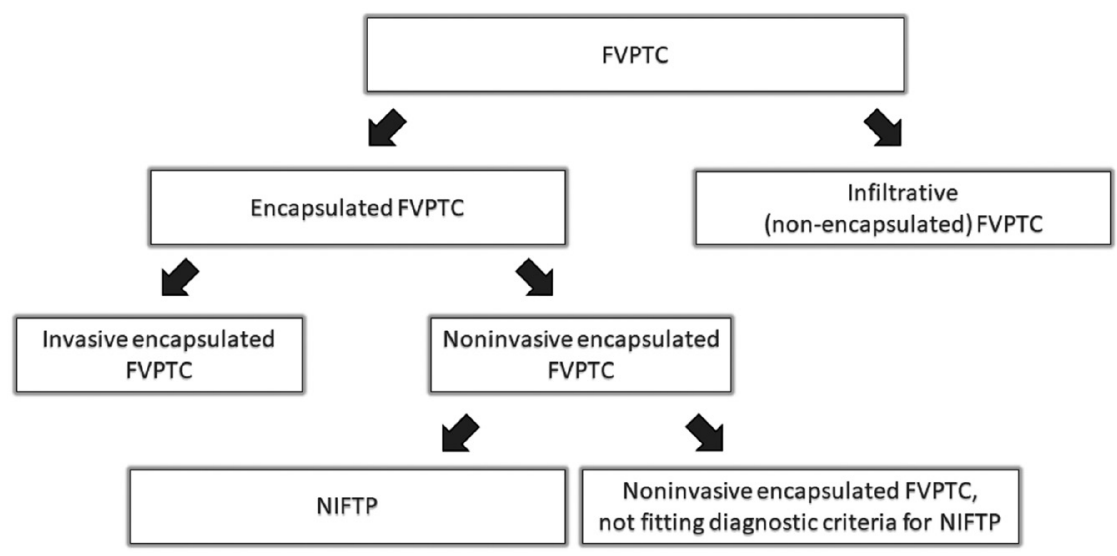

\section{Figure 1}

Classification of FVPTC. FVPTC, follicular variant of papillary thyroid carcinoma; NIFTP, noninvasive follicular thyroid neoplasm with papillary-like nuclear features. node recurrence, one had persistent disease and five had detectable serum thyroglobulin ( $\mathrm{Tg}$ ) concentration) (4). On the basis of the obtained results and literature review, the authors proposed that the name 'noninvasive encapsulated FVPTC' be replaced with the term 'noninvasive follicular thyroid neoplasm with papillary-like nuclear features (NIFTP)' to emphasise the indolent course of the disease and to eliminate the word 'carcinoma' and thus its clinical and psychological consequences (4). The term NIFTP was adopted by the scientific community $(5,6)$ and included in the latest edition of the World Health Organization (WHO) Classification of Tumours of Endocrine Organs in the group 'follicular patterned neoplasms with borderline clinical behaviour', along with follicular tumour of uncertain malignant potential (FT-UMP) and well differentiated tumour of uncertain malignant potential (WDT-UMP) (7).

Although more than 3 years have passed since the introduction of the term NIFTP, there are still controversies concerning the criteria for the diagnosis of NIFTP based on postoperative examination, the potential for preoperative differentiation of NIFTP from other variants of FVPTC and the clinical behaviour, treatment and monitoring of patients with NIFTP.

\section{Epidemiology}

When Nikiforov et al. proposed the reclassification of noninvasive EFVPTC as NIFTP, they estimated that the new diagnosis would affect more than 45,000 patients worldwide each year (4). The predictions, which were based on retrospective data from four institutions (three Italian and one American), resulted in a calculated rate of NIFTP of $18.6 \%$ among all PTC cases (4). After more than 3 years from the introduction of the new nomenclature, it appears that the initial calculations were overestimated $(8,9,10,11,12,13,14,15,16,17,18,19,20,21)$.
According to the meta-analysis conducted by Bychkov et al. (25 studies, 46,948 patients with PTC), the prevalence of NIFTP is $9.1 \%$ (95\% CI, $6.0-12.7 \%)$ of all PTC cases; the rate of NIFTP is considerably lower in the Asian population $(1.6 \%, 95 \% \mathrm{CI}, 0.9-2.5 \%)$ than in Western Europe and America (13.3\%, 95\% CI, 9.0-18.3\%) (22). The observed difference in NIFTP prevalence between Asian and non-Asian countries can be attributed to ethnic variance (different mutation profiles of thyroid cancer) (23), differences in the interpretation of histological criteria (24) and differences in clinical practice (lower resection rates in patients with indeterminate thyroid cytologies) (25). Prevalence of NIFTP in PTC in selected Western European and American studies compared to Asian studies is presented in Table 1.

Large differences in the incidence of NIFTP have been reported not only between countries but also between different institutions in the same country (USA, 4.0-27.0\%; Korea, 1.3-2.7\%), which, at least in part, may be attributable to different study designs (retrospective/ prospective), sources of data collection (via cytologic/ surgical pathology database) and the inclusion or exclusion of microcarcinomas from NIFTP.

The latest meta-analysis conducted by Ruanpeng et al. (11 studies, 27,866 patients with PTC) indicated that the prevalence of NIFTP among PTC is 4.4\% (95\% CI, 2.0-9.0\%) (26), which is definitely lower than that reported by Bychkov. Such a difference may be surprising because both meta-analyses were partially based on the same studies $(22,26)$. The reason for this difference may be that the study by Ruanpeng enrolled more patients from Asian countries (in which the prevalence of NIFTP is several times lower than in non-Asian populations): the proportion of Asian patients in the study by Bychkov was $63.7 \%$ (29,896 out of 46,948 patients with PTC), whereas that in the study by Ruanpeng was $77.8 \%$ (21,667 out of $27,866)$.

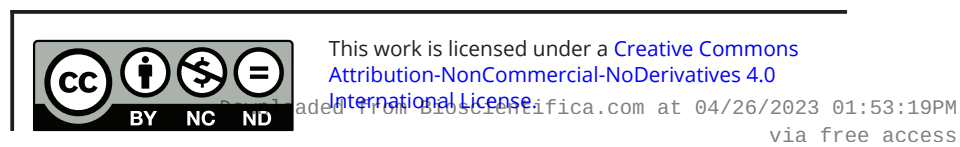


Table 1 Prevalence of NIFTP in PTC in selected Western European and American studies compared to Asian studies.

\begin{tabular}{|c|c|c|c|c|}
\hline Geographical region & Source & Country & Total & NIFTP $\%$ \\
\hline \multirow[t]{9}{*}{ Western Europe and America } & Jaconi et al. (8) & Italy & $14 / 51$ & 27.5 \\
\hline & Kopczyński et al. (9) & Poland & $12 / 214$ & 5.6 \\
\hline & Canberk et al. (10) & Portugal & $74 / 3466$ & 2.1 \\
\hline & Li et al. (11) & USA & $17 / 252$ & 6.7 \\
\hline & Mao et al. (12) & USA & $32 / 454$ & 7.0 \\
\hline & Point du Jour et al. (13) & USA & $17 / 420$ & 4.0 \\
\hline & Wong et al. (14) & USA & $94 / 348$ & 27.0 \\
\hline & Parente et al. (15) & Canada & $102 / 4790$ & 2.1 \\
\hline & Eskander et al. (16) & Canada & $318 / 2846$ & 11.2 \\
\hline \multirow[t]{5}{*}{ Asia } & Hirokawa et al. (17) & Japan & $54 / 10,076$ & 0.5 \\
\hline & Kim et al. (18) & Korea & $73 / 2853$ & 2.5 \\
\hline & Lee et al. (19) & Korea & $21 / 769$ & 2.7 \\
\hline & Cho et al. (20) & Korea & $95 / 6269$ & 1.5 \\
\hline & Seo et al. $(21)^{b}$ & Korea & $238 / 18,819$ & 1.3 \\
\hline
\end{tabular}

aCalculations based on pathological reports. ${ }^{b}$ Data collected from eight institutions in Korea.

NIFTP, noninvasive follicular thyroid neoplasm with papillary-like nuclear features; PTC, papillary thyroid carcinoma.

\section{Molecular pathogenesis of NIFTP}

At the molecular level, NIFTP is characterised by the lack of BRAF V600E and BRAF V600E-like mutations or other high-risk mutations and a high rate of $R A S$ mutations. This is similar to follicular-pattern thyroid tumours, including follicular adenoma (FA), follicular thyroid carcinoma (FTC) and FVPTC $(4,27,28,29,30)$. It is suggested that NIFTP represents an anticipated precursor of invasive EFVPTC $(4,31)$. Activating mutations of the RAS gene are detected in $30-67 \%$ of NIFTP cases; the most common mutation affects NRAS, followed by HRAS and KRAS genes (4, 27, $28,29,30,32,33)$. Other less common genetic alterations found in NIFTP include PPARG fusions $(4,27,33)$, THADA fusions $(4,27)$ and BRAF K600E mutations $(4,28,31,32)$. Rarely, tumours harbouring high-risk mutations such as TERT promoter mutations and ETV6-NTRK3 fusions may have a morphology that overlaps with NIFTP (30, 34). However, the presence of any high-risk mutations constitutes the exclusion criterion for NIFTP diagnosis and should trigger an exhaustive search for morphologic exclusion criteria (35).

\section{Evolution of the diagnostic criteria of NIFTP}

The diagnosis of NIFTP can only be made after histological examination of the entire tumour removed during surgery and is based on strictly defined inclusion and exclusion criteria $(4,35)$. According to the original criteria, histological examination NIFTP should show an encapsulated or clearly demarcated nodule, with cells exhibiting a follicular growth pattern and nuclei typical of PTC. NIFTP should not display any features of vascular or capsular invasion, tumour necrosis, high mitotic activity (defined as three or more mitoses per ten highpower fields $(\times 40)$ ), papillae $>1 \%$, psammoma bodies or morphologic characteristics of other variants of PTC, such as tall cell, cribriform-morular and solid/trabecular variants (4).

The absence of capsular and vascular invasion is critical to the diagnosis of NIFTP (4). To ensure this issue, the entire tumour capsule or tumour normal interface should be submitted for histological examination (36). For large lesions, stepwise submission of sections (with an initial generous but limited sampling, followed by submission of the remainder of the tumoral capsule if no vascular or capsular invasion is initially detected) is acceptable (36). However, there is no clear recommendation on how to evaluate effectively the entire tumour capsule. A recently published study by Oh et al. presented a modified transversevertical gross examination method with additional vertical cuts at the upper and lower ends of thyroid nodules (37). This modified transverse-vertical gross examination method was more effective than the conventional transverse examination method for the detection of capsular invasion and might allow a better differential diagnosis between NIFTP and invasive EFVPTC (37).

It should be noted that not all cases previously diagnosed as noninvasive EFVPTC meet the exact definition of NIFTP, which is more rigorous (13) (Fig. 1).

The introduction of the term NIFTP led to a discussion on the diagnostic criteria used. Particularly questionable was the presence of papillary structures associated with the occurrence of $B R A F$ V600E mutations and regional lymph node metastases $(18,20,38)$. These features (the presence of papillae, BRAF V600E mutations and lymph node 
metastases) are characteristic of classic PTC (cPTC) rather than FVPTC, which raises concerns that the incorrect application of diagnostic criteria for NIFTP can lead to misdiagnosis of cPTC with a prominent follicular pattern as NIFTP (35). As a result, revised diagnostic criteria for NIFTP have been proposed (35). The criterion 'less than $1 \%$ papillae' was changed to 'no well-formed papillae'. In cases showing pronounced nuclear features of PTC (nuclear score 3), the entire tumour should be examined to exclude the presence of papillary structures. In addition, secondary criteria (molecular testing for BRAF V600E and other high-risk mutations and immunohistochemistry for $B R A F$ V600E) were added that may be helpful but are not required for the diagnosis of NIFTP (35). A summary of the initial and revised NIFTP diagnostic criteria is presented in Table 2. The change of diagnostic criteria for NIFTP has reduced the number of NIFTP diagnoses (20).

Another controversy over diagnostic criteria of NIFTP concerns the size of the tumour and multifocality. According to the original study by Nikiforov et al., neither tumour size nor multifocality were included to establish the diagnosis criteria of NIFTP (4). However, the study did not include subcentimeter, large $(\geq 4 \mathrm{~cm})$ and multifocal tumours, which raises doubts as to whether such tumours can be classified as NIFTPs.

The recommendations specify that the diagnosis of NIFTP should not be based on retrospective interpretation of pathologic reports $(6,39)$.

\section{Clinical and ultrasonographic features}

In clinical practice, NIFTP presents as a single nodule (10) or a lesion in the context of a multinodular background $(27,40,41)$. The multifocal form of NIFTP is present in
$2.7-14.7 \%$ of patients $(10,40,42)$. The coexistence of a malignant lesion in the same or in the second lobe of the thyroid may affect $14.9-46.3 \%$ of NIFTP patients (it most often coexists with papillary thyroid microcarcinoma) $(10,21,41)$.

On ultrasound (US) examination, NIFTP is usually a well-circumscribed, oval-to-round nodule with regular margins and variable echogenicity, ranging from markedly hypoechoic to hypoechoic, isoechoic and heterogeneous $(27,41,43,44,45)$. Such significant differences in the reported echogenicity of NIFTPs are not surprising because echogenicity is considered to be the feature with the lowest inter-observer agreement $(46,47,48)$. The presence of calcifications is rare $(27,41,44)$. On Power Doppler US, NIFTPs are mostly hypervascular $(45,49)$, and usually present a mixed (peripheral and intranodular) type of vascularisation (49).

On US, NIFTP corresponds to a lesion with a low or intermediate suspicion pattern according to the ultrasonographic classification of the American Thyroid Association (ATA) $(44,50,51)$. Similarly, according to the Thyroid Imaging Reporting and Data System (TI-RADS) proposed by the American College of Radiology (ACR), nodules consistent with NIFTP are mostly qualified as TR3 (mildly suspicious) and TR4 (moderately suspicious) (52). The exclusion of NIFTPs from malignant tumours decreases the risk of malignancy (ROM) of the ATA and TI-RADS categories to a degree dependent on the pre-test probability and prevalence of NIFTP in the studied population $(52,53)$.

\section{NIFTP in fine-needle aspiration biopsy}

NIFTP is a postoperative diagnosis and cannot be diagnosed solely on the basis of fine-needle aspiration

Table 2 Initial and revised diagnostic criteria for NIFTP according to Nikiforov et al. $(4,35)$.

\begin{tabular}{|c|c|c|}
\hline \multirow[b]{2}{*}{ Initial diagnostic criteria for NIFTP } & \multicolumn{2}{|c|}{ Revised diagnostic criteria for NIFTP } \\
\hline & Primary & Secondary $^{a}$ \\
\hline Encapsulation or clear demarcation & Encapsulation or clear demarcation & $\begin{array}{l}\text { Lack of BRAF V600E mutation detected by } \\
\text { molecular assays or immunohistochemistry }\end{array}$ \\
\hline $\begin{array}{l}\text { Follicular growth pattern with: } \\
\leq 1 \% \text { papillae }\end{array}$ & $\begin{array}{l}\text { Follicular growth pattern with: } \\
\text { No well-formed papillae }\end{array}$ & $\begin{array}{l}\text { Lack of BRAF V600E-like mutations or other } \\
\text { high-risk mutations (TERT, TP53) }\end{array}$ \\
\hline No psammoma bodies & $\overline{\text { No psammoma bodies }}$ & \\
\hline$<30 \%$ solid/trabecular/insular & $<30 \%$ solid/trabecular/insular & \\
\hline growth pattern & growth pattern & \\
\hline Nuclear score, 2-3 & Nuclear score, 2-3 & \\
\hline No vascular or capsular invasion & No vascular or capsular invasion & \\
\hline No tumour necrosis & No tumour necrosis & \\
\hline No high mitotic activity & No high mitotic activity & \\
\hline
\end{tabular}

aSecondary criteria are helpful but not required for NIFTP diagnosis.

NIFTP, noninvasive follicular thyroid neoplasm with papillary-like nuclear features.

https://ec.bioscientifica.com https://doi.org/10.1530/EC-19-0566 (c) 2020 The authors Published by Bioscientifica Ltd

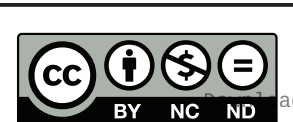

This work is licensed under a Creative Commons Attribution-NonCommercial-NoDerivatives 4.0 International ticense ifica com at 04/26/2023 01:53:19PM 
biopsy (FNAB); however, certain cytological features may raise suspicion of $\operatorname{NIFTP}(54,55)$. FNAB samples usually show scant colloid with abundant small clusters of follicular cells and microfollicles and nuclear atypia including enlarged, oval-shaped nuclei, nuclear grooves, chromatin clearing, rare nuclear pseudo-inclusions and no true papillae $(56,57,58)$.

In preoperative cytology, NIFTP can belong to any of the six categories of the Bethesda System for Reporting Thyroid Cytopathology (TBSRTC), although it is most often found in so-called 'indeterminate' categories (59). A meta-analysis carried out by Bongiovanni et al., which included 15 studies and 915 histologically confirmed cases of NIFTP with corresponding cytology, indicated the following distribution of NIFTP in the TBSRTC categories: nondiagnostic, 3\%; benign, 10\%; atypia of undetermined significance or follicular lesion of undetermined significance (AUS/FLUS), 30\%; follicular neoplasm or suspicious for a follicular neoplasm (FN/SFN), 21\%; suspicious for malignancy (SM), 24\% and malignant, 8\% (59).

Recently updated Bethesda classification recommends subclassification of the AUS/FLUS category (54). When considering AUS/FLUS subcategories, NIFTP is most often classified as architectural atypia (AUS-A) or cytologic and architectural atypia (AUS-C\&A) (60). It is not surprising, since NIFTP smears are characterised by the presence of microfollicles. Subcategories can help in the prediction of the type of neoplasia (60). AUS-A and AUS-C\&A subcategories can rise the suspicion of NIFTP and help in selection of appropriate molecular tests.

To raise the clinicians' awareness of the fact that NIFTP constitutes a substantial proportion of the 'malignancies' hidden in TBSRTC categories, optional education notes suggesting a diagnosis of NIFTP may be used by cytopathologists (27).
The reclassification of NIFTP as a non-malignant lesion decreases the ROM in most Bethesda categories; the scale of the impact differs significantly among various institutions $(9,11,61,62,63,64,65,66,67,68,69,70)$. According to the latest large meta-analysis conducted by Vuong et al. (14 studies, 14,153 resected nodules), the highest absolute decrease in ROM was observed in SM, FN/SFN and AUS/FLUS categories (15.8\%, 10.6\% and 9.5\%, respectively) (71). The ROM changes in particular Bethesda categories are significantly lower in Asian than in Western countries $(71,72)$, which is attributed to a lower prevalence of NIFTP in the Asian population. Another meta-analysis assessing the impact of NIFTP on the ROM in patients undergoing surgery for SM or malignant FNAB findings shows that the inclusion of NIFTP leads to a reduction in the ROM for SM and malignant diagnostic categories by $14 \%$ and $3 \%$, respectively (73). A comparison of the results of both meta-analyses with the data reported by Cibas et al. (54) is presented in Table 3. All the studies included in these meta-analyses used the diagnostic criteria for NIFTP proposed initially by Nikiforov in 2016. Further studies evaluating the impact of NIFTP on ROM should be conducted using the revised criteria.

\section{Attempts at preoperative identification of NIFTP}

Since NIFTP is considered a non-malignant lesion and requires a different management than carcinoma, including a different scope of surgical treatment, it would be highly useful to preoperatively differentiate NIFTP from non-NIFTP lesions.

Several studies have shown that NIFTP can be differentiated from cPTC in cytological examination based

Table 3 ROM changes in Bethesda categories after reclassification of NIFTP according to Vuong et al. (71) and Bongiovanni et al. (73) in comparison with data reported by Cibas et al. (54).

\begin{tabular}{|c|c|c|c|}
\hline \multirow[b]{2}{*}{$\begin{array}{l}\text { Diagnostic } \\
\text { category }\end{array}$} & \multicolumn{3}{|c|}{ Data reported by Cibas et al. } \\
\hline & ROM if NIFTP = CA (\%) & ROM if NIFTP $\neq$ CA (\%) & $\begin{array}{c}\text { Absolute ROM } \\
\text { decrease (\%) }\end{array}$ \\
\hline ND & $5-10$ & $5-10$ & 0 \\
\hline Benign & $0-3$ & $0-3$ & 0 \\
\hline AUS/FLUS & $10-30$ & $6-18$ & $4-12$ \\
\hline FN/SFN & $25-40$ & $10-40$ & $0-15$ \\
\hline SM & $50-75$ & $45-60$ & $5-15$ \\
\hline Malignant & $97-99$ & $94-96$ & 3 \\
\hline
\end{tabular}

\begin{tabular}{c}
\hline Vuong et al. \\
\hline Absolute ROM \\
decrease (\%) \\
\hline 2.2 \\
1.6 \\
9.5 \\
10.6 \\
15.8 \\
2.3
\end{tabular}

\begin{tabular}{c} 
Bongiovanni et al. \\
\hline Absolute ROM decrease \\
$(\%)$ \\
\hline- \\
- \\
- \\
- \\
14 \\
3
\end{tabular}

AUS/FLUS, atypia of undetermined significance or follicular lesion of undetermined significance; CA, carcinoma; FN/SNF, follicular neoplasm or suspicious for follicular neoplasm; ND, nondiagnostic; NIFTP, noninvasive follicular thyroid neoplasm with papillary-like nuclear features; ROM, risk of malignancy; SM, suspicious for malignancy.

https://ec.bioscientifica.com https://doi.org/10.1530/EC-19-0566 (c) 2020 The authors Published by Bioscientifica Ltd

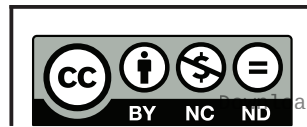

This work is licensed under a Creative Commons Attribution-NonCommercial-NoDerivatives 4.0 Internationab ticense.ifica.com at 04/26/2023 01:53:19PM 
on a combination of certain features, such as the presence of true papillae, pseudo-inclusions, psammomatous calcifications, multinucleate giant cells and follicular architecture $(57,74,75,76)$. Moreover, NIFTP and cPTC have different molecular profiles: NIFTP is characterised by the frequent occurrence of $R A S$ mutations and the lack of BRAF V600E mutations, whereas these are often encountered in cPTC $(4,77)$. Similarly, the cytological features make it possible to differentiate NIFTP from most benign lesions including FAs $(57,58,78,79)$. The most demanding task is to preoperatively differentiate NIFTP from other FVPTCs.

Certain ultrasound features may be helpful for distinguishing NIFTP from infiltrative FVPTC (IFVPTC) $(51,80,81)$. NIFTP most commonly presents as a roundto-oval nodule with smooth margins, whereas IFVPTC is characterised by an irregular shape and spiculated margins, which are associated with the infiltrative growth of this tumour (51). Consequently, a high-suspicion pattern on US is significantly more frequent in IFVPTC than in NIFTP $(51,82)$. However, studies suggest that ultrasonography is insufficient for differentiating NIFTP from invasive EFVPTC $(80,81,83)$. Both tumours show a similar appearance in cytological examinations as well $(58,76,80,83,84)$. This is not surprising given that NIFTP can be differentiated from invasive EFVPTC by the exclusion of capsular and vascular invasion based on histological examination of the entire tumour along with the capsule $(4,35)$.

The molecular profile of these tumours may prove helpful for the preoperative differentiation of NIFTP from invasive EFVPTC. Although RAS mutations occur in both tumour types with similar frequency $(29,30,85), B R A F$ $\mathrm{V} 600 \mathrm{E}$ and TERT promoter mutations are not found in NIFTP, whereas they may be present in a small percentage of invasive EFVPTC $(29,83,85,86,87)$.

Because NIFTP is most commonly found among indeterminate categories in preoperative cytology, some NIFTP patients are diagnosed using commercially available molecular tests. The most widely used tests, Afirma Gene Expression Classifier (Afirma GEC) and ThyroSeq, were developed to reduce the number of thyroidectomies in patients with indeterminate nodules. Most cases of NIFTP are classified as 'suspicious' in GEC $(27,32,34,41,88)$ and 'positive results' in ThyroSeq tests ('HR mutation group' in ThyroSeq v2 and 'RAS-like-group' in ThyroSeq v3) (27, $32,34,88,89,90)$.

To sum up, the existence of overlapping features between NIFTP and invasive EFVPTC is evident. A diagnosis of NIFTP may be suggested but cannot be certain until a full histological examination of the material obtained during surgery has been performed. A low or intermediate suspicion pattern on US combined with indeterminate cytology and a 'suspicious' result of GEC/presence of RAS mutation in ThyroSeq should raise suspicion of NIFTP and lead the clinician to consider less aggressive treatment options.

\section{Doubts concerning the indolent behaviour of NIFTP}

According to Nikiforov's original study, NIFTP has an indolent behaviour and an extremely good prognosis (4). Since the introduction of the term NIFTP, many studies have confirmed the low risk of adverse outcomes, including in multifocal, large and small tumours ( $\geq 4$ and $\leq 1 \mathrm{~cm}$, respectively).

A study by Rosario et al. (50) included 129 patients with NIFTP $>1 \mathrm{~cm}$, of whom 65 underwent lobectomy and 64 underwent total thyroidectomy, with no patients treated with radioiodine. During a follow-up of 12-146 months (median, 72 months) after surgery, none of the patients developed structural disease, and the concentrations of $\mathrm{Tg}$ and anti-Tg antibodies were stable in all patients (50).

In another study, 94 cases of EFVPTC (77 noninvasive FVPTC and 17 invasive FVPTC), including multifocal $(n=20)$ and bilateral $(n=13)$ tumours ranging in size from 0.7 to $9.5 \mathrm{~cm}$ (mean, $3.3 \mathrm{~cm}$ ), were observed for 1.2-12.5 years (median, 11.8 years) after treatment (lobectomy alone in 41 , thyroidectomy alone in 34 , completion thyroidectomy in 19 and combination with postoperative radioactive iodine ablation in 25 patients); there was no evidence of recurrence based on biochemical or structural disease (42). The outcomes were identical regardless of the presence of capsular and lymphovascular invasion (42).

A recently published multi-institutional Korean study identified 238 cases of NIFTP, including 152 tumours with a diameter $\geq 1 \mathrm{~cm}$ (35\% of patients underwent total thyroidectomy, $65 \%$ underwent lobectomy or isthmectomy and another 23\% received radioiodine remnant ablation therapy). The mean follow-up was 37.7 months, and no patient with NIFTP had evidence of lymph node, or distant metastasis or disease recurrence during the follow-up period (21).

These and many other studies, including those with a smaller number of cases, confirm that the application of strict criteria for the diagnosis of NIFTP means that metastasis and BRAF mutations are not observed (13, $91,92)$. Moreover, the available data indicate that both large NIFTPs (with a diameter $\geq 4 \mathrm{~cm}$ ) and tumours with

This work is licensed under a Creative Commons Attribution-NonCommercial-NoDerivatives 4.0 Internationad ticense ifica.com at 04/26/2023 01:53:19PM 
a diameter $\leq 1 \mathrm{~cm}$ that meet the NIFTP criteria (not included in the original study because of limited or lack of supportive data) do not differ from their 'average size' counterparts and show exceptionally indolent behaviour $(93,94,95,96)$.

Although most publications confirm the favourable course of NIFTP, there are a few reports suggesting that lesions diagnosed as NIFTP can be associated with metastases.

A study by Cho et al. (20) examined the frequency of lymph node metastasis in a cohort of 154 patients with EFVPTC. When the cut-off of $1 \%$ papillae was used, the rate of lymph node metastasis was $3 \%$ and the rate of $B R A F$ V600E mutation was $10 \%$ in noninvasive tumours. When the absence of a papillary structure was applied as a rigid diagnostic criterion, no BRAF V600E mutation was found in any of the tumours. However, central lymph node micrometastases still occurred in 3\% of noninvasive tumours despite the absence of papillae and BRAF V600E mutations (20). It should be emphasised that prophylactic central neck dissection was performed in the study, which might have increased the incidence of clinically significant lymph node metastases.

A study by Parente et al. (15) found that the rate of adverse oncologic events was 6\% (6/102) in patients with NIFTP; these included metastases to regional lymph nodes in five patients and distant metastases (to lungs) in one patient. The study did not include routine central neck dissection in the absence of preoperatively suspicious lymph nodes. Moreover, tumours with any true papillae were excluded, but no molecular tests were performed, especially for BRAF V600E mutations (15).

Another study (38) reported 3/43 noninvasive EFVPTC cases with lymph node metastases. However, the metastases originated from noninvasive EFVPTC in only one case, whereas in the other cases, they were derived from coexisting conventional PTCs. The only noninvasive EFVPTC tumour with metastases tested negative for $B R A F$ V600E mutation and lacked well-formed papillae (38).

Finally, a recent controversial study conducted by Canadian researchers led by Eskander (16), which included 318 patients with NIFTP diagnosed based on pathological reports, indicated that during a median follow-up of 15.3 years, disease failure (defined as death from thyroid cancer or a recurrence event) occurred in 30 patients (9.4\%) (16). The main limitation of the study was that it based the diagnosis of NIFTP on a thorough review of pathology reports, without at least reviewing the slides, which is inconsistent with current recommendations (6, 39). Moreover, as the authors themselves state, the quality of the reports was poor or very poor in $50 \%$ of cases. In particular, the availability of information on the presence of features such as true papillae, psammoma bodies, infiltrative borders, tumour necrosis, high mitotic rate and morphologic features of an aggressive variant were 'unstated' in 87\%, 74\%, 89\%, 95\%, 90\% and 90\% of cases, respectively (16). These limitations give rise to a reasonable suspicion that at least some of the tumours considered as NIFTP were in fact carcinomas.

To conclude, some of the described cases of adverse outcomes of NIFTP could be related to a misdiagnosis; the exclusion of the BRAF V600E mutation in Parente's study, as well as basing the diagnosis of NIFTP on slides review rather than on pathology reports in Eskander's study, might have resulted in a change of diagnosis to malignancy. However, some of the cases described previously do indeed appear to be NIFTPs.

Taken together, the available data indicate that NIFTP diagnosed according to strict inclusion and exclusion criteria has an extremely indolent clinical behaviour, even when treated conservatively with lobectomy and without radioactive iodine therapy. Nevertheless, it cannot be considered as a benign lesion. The risk of adverse outcomes, including metastases, is very low but not negligible.

\section{Treatment and monitoring}

According to the ATA Thyroid Nodules and Differentiated Thyroid Cancer Guidelines, patients with tumours diagnosed as NIFTP are subject to the same recommendations as patients with low risk for recurrence differentiated thyroid carcinoma, namely, lobectomy is sufficient, remnant ablation is not recommended and thyrotropin target levels should be kept between 0.5 and $2 \mathrm{mIU} / \mathrm{L}$ (5).

However, since the definitive diagnosis of NIFTP can only be made based on postoperative histological examination, total thyroidectomy remains an acceptable option for some cases of NIFTP. This was emphasised in the recommendations of the American Head and Neck Society Endocrine Section Consensus Statement (39). The decision on the extent of surgical treatment (lobectomy vs total thyroidectomy) should be made on the basis of physical examination, ultrasound data and molecular and patient/endocrine characteristics. In particular, the patient should be informed of the potential need for a second surgery and should be ready to undergo such a surgery when lobectomy is considered (39).

Decisions on the extent of surgery should consider that bilateral disease and multifocal disease are part of the 
spectrum of NIFTP neoplasms $(10,40,42)$. The coexistence of malignant lesions in the same or the other thyroid lobe may affect up to $15-46 \%$ of NIFTP patients $(10,21,41)$. In the study by Canberk et al., $15 \%$ of NIFTP cases $(11 / 74)$ were accompanied by malignant lesions in the contralateral thyroid lobe, including five PTCs, five microcarcinoma FVPTCs and one IFVPTC; two of the contralateral malignancies showed microscopic extrathyroidal extension (10). When deciding on lobectomy, the contralateral lobe must be assessed with special caution to prevent missing the coexistence of a malignant lesion.

There are currently no recommendations regarding the monitoring of patients with NIFTP. The ATA Thyroid Nodules and Differentiated Thyroid Cancer Guidelines Task Force suggest that 'occasional monitoring with serum $\mathrm{Tg}$ and neck ultrasound can be considered, depending upon patient's context, but this is not mandatory' (5). Some authors suggest that after complete resection of NIFTP, negative postoperative assessment (defined by a $\mathrm{Tg}$ concentration $\leq 2 \mathrm{ng} / \mathrm{mL}$ in patients undergoing total thyroidectomy and $\leq 10 \mathrm{ng} / \mathrm{mL}$ in those undergoing lobectomy, in the absence of anti-Tg antibodies and neck ultrasonography without abnormalities) can be used to exclude the need for long-term repetition of these tests (97).

However, in the light of recent reports of a possible adverse outcome of NIFTP $(15,16,20,38)$, monitoring of these patients seems reasonable. The frequency and length of monitoring of NIFTP patients should be considered individually depending on the presence of risk factors (a surgical history of lobectomy/thyroidectomy, the presence of thyroid nodules in the remaining lobe or the results of postoperative assessment).

\section{Conclusions and perspectives}

Three years after its introduction into clinical practice, the diagnosis of NIFTP still poses a challenge for clinicians, ultrasonographers and cytopathologists. Although the diagnosis is postoperative, accurate preoperative assessment may raise suspicion of NIFTP and indicate a more conservative management. Positive results in the GEC and ThyroSeq molecular tests may be associated with NIFTP and should therefore be interpreted in the context of ultrasonographic and cytological features.

Although lobectomy is sufficient for the treatment of NIFTP, total thyroidectomy remains an option for some patients, particularly for those who do not accept the need for monitoring the remaining thyroid lobe and the risk of emerging indications for a second surgery.
Finally, NIFTP does not represent a benign lesion, but rather a 'low-risk neoplasm'; although the risk of adverse events, including lymph node metastases, is small, it cannot be underestimated. Long-term prospective studies are required to assess the actual prevalence and outcomes of NIFTP.

\section{Declaration of interest}

The authors declare that there is no conflict of interest that could be perceived as prejudicing the impartiality of this review.

\section{Funding}

The project was financed under the Regional Initiative of Excellence programme of the Minister of Science and Higher Education (project no. 024/RID/2018/19; amount of financing: 11,999,000 zł).

\section{References}

1 Yu XM, Schneider DF, Leverson G, Chen H \& Sippel RS. Follicular variant of papillary thyroid carcinoma is a unique clinical entity: a population-based study of 10,740 cases. Thyroid 201323 1263-1268. (https://doi.org/10.1089/thy.2012.0453)

2 Rivera M, Ricarte-Filho J, Knauf J, Shaha A, Tuttle M, Fagin JA \& Ghossein RA. Molecular genotyping of papillary thyroid carcinoma follicular variant according to its histological subtypes (encapsulated vs infiltrative) reveals distinct BRAF and RAS mutation patterns. Modern Pathology 201023 1191-1200. (https://doi.org/10.1038/ modpathol.2010.112)

3 Liu J, Singh B, Tallini G, Carlson DL, Katabi N, Shaha A, Tuttle RM \& Ghossein RA. Follicular variant of papillary thyroid carcinoma: a clinicopathologic study of a problematic entity. Cancer $2006 \mathbf{1 0 7}$ 1255-1264. (https://doi.org/10.1002/cncr.22138)

4 Nikiforov YE, Seethala RR, Tallini G, Baloch ZW, Basolo F, Thompson LDR, Barletta JA, Wenig BM, Al Ghuzlan A, Kakudo K, et al. Nomenclature revision for encapsulated follicular variant of papillary thyroid carcinoma: a paradigm shift to reduce overtreatment of indolent tumors. JAMA Oncology 20162 1023-1029. (https://doi.org/10.1001/jamaoncol.2016.0386)

5 Haugen BR, Sawka AM, Alexander EK, Bible KC, Caturegli P, Doherty GM, Mandel SJ, Morris JC, Nassar A, Pacini F, et al. American Thyroid Association guidelines on the management of thyroid nodules and differentiated thyroid cancer task force review and recommendation on the proposed renaming of encapsulated follicular variant papillary thyroid carcinoma without invasion to noninvasive follicular thyroid neoplasm with papillary-like nuclear features. Thyroid 201727 481-483. (https://doi.org/10.1089/ thy.2016.0628)

6 Baloch ZW, Harrell RM, Brett EM, Randolph G, Garber JR \& AACE Endocrine Surgery Scientific Committee and Thyroid Scientific Committee. Managing thyroid tumors diagnosed as non-invasive follicular tumor with papillary like nuclear features (NIFTP). Endocrine Practice 2017 [epub]. (https://doi.org/10.4158/ EP171940.DSC)

7 Lloyd RV, Osamura RY, Klöppel G \& Rosai J. WHO Classification of Tumours of Endocrine Organs, 4th ed. Lyon, France: International Agency for Research on Cancer, 2017.

8 Jaconi M, Manzoni M, Pincelli AI, Giardini V, Scardilli M, Smith A, Fellegara G \& Pagni F. The impact of the non-invasive follicular thyroid neoplasm with papillary-like nuclear feature terminology in the routine diagnosis of thyroid tumours. Cytopathology $2017 \mathbf{2 8}$ 495-502. (https://doi.org/10.1111/cyt.12459) 
9 Kopczyński J, Suligowska A, Niemyska K, Palyga I, Walczyk A, Gąsior-Perczak D, Kowalik A, Hińcza K, Mężyk R, Góźdź S, et al. The influence of the reclassification of NIFTP as an uncertain tumour on risk of malignancy for the diagnostic categories according to the Bethesda system for reporting thyroid cytopathology. Endokrynologia Polska 201970 232-236. (https://doi.org/10.5603/EP.a2019.0008)

10 Canberk S, Montezuma D, Taştekin E, Grangeia D, Demirhas MP, Akbas M, Tokat F, Ince U, Soares P \& Schmitt F. 'The other side of the coin': understanding noninvasive follicular tumor with papillary-like nuclear features in unifocal and multifocal settings. Human Pathology 201986 136-142. (https://doi.org/10.1016/j.humpath.2018.10.040)

11 Li W, Sciallis A, Lew M, Pang J \& Jing X. Implementing noninvasive follicular thyroid neoplasm with papillary-like nuclear features may potentially impact the risk of malignancy for thyroid nodules categorized as AUS/FLUS and FN/SFN. Diagnostic Cytopathology 2018 46 148-153. (https://doi.org/10.1002/dc.23866)

12 Mao ML, Joyal T, Picado O, Kerr D, Lew JI \& Farrá JC. Noninvasive follicular thyroid neoplasm with papillary-like nuclear features reclassification and its impact on thyroid malignancy rate and treatment. Journal of Surgical Research 2018230 47-52. (https://doi. org/10.1016/j.jss.2018.04.013)

13 Point du Jour K, du Jour KP, Schmitt AC, Chen AY \& Griffith CC. Application of strict criteria for noninvasive follicular thyroid neoplasm with papillary-like nuclear features and encapsulated follicular variant papillary thyroid carcinoma: a retrospective study of 50 tumors previously diagnosed as follicular variant PTC. Endocrine Pathology 201829 35-42. (https://doi.org/10.1007/s12022017-9509-0)

14 Wong KS, Strickland KC, Angell TE, Nehs MA, Alexander EK, Cibas ES, Krane JF, Howitt BE \& Barletta JA. The flip side of NIFTP: an increase in rates of unfavorable histologic parameters in the remainder of papillary thyroid carcinomas. Endocrine Pathology 2017 28 171-176. (https://doi.org/10.1007/s12022-017-9476-5)

15 Parente DN, Kluijfhout WP, Bongers PJ, Verzijl R, Devon KM, Rotstein LE, Goldstein DP, Asa SL, Mete O \& Pasternak JD. Clinical safety of renaming encapsulated follicular variant of papillary thyroid carcinoma: is NIFTP truly benign? World Journal of Surgery 201842 321-326. (https://doi.org/10.1007/s00268-017-4182-5)

16 Eskander A, Hall SF, Manduch M, Griffiths R \& Irish JC. A population-based study on NIFTP incidence and survival: is NIFTP really a 'benign' disease? Annals of Surgical Oncology 201926 1376-1384. (https://doi.org/10.1245/s10434-019-07187-0)

17 Hirokawa M, Higuchi M, Suzuki A, Hayashi T, Kuma S \& Miyauchi A. Noninvasive follicular thyroid neoplasm with papillary-like nuclear features: a single-institutional experience in Japan. Endocrine Journal 201764 1149-1155. (https://doi.org/10.1507/endocrj.EJ17-0214)

18 Kim TH, Lee M, Kwon AY, Choe JH, Kim JH, Kim JS, Hahn SY, Shin JH, Chung MK, Son YI, et al. Molecular genotyping of the non-invasive encapsulated follicular variant of papillary thyroid carcinoma. Histopathology 201872 648-661. (https://doi. org/10.1111/his.13401)

19 Lee SE, Hwang TS, Choi YL, Kim WY, Han HS, Lim SD, Kim WS, Yoo YB \& Kim SK. Molecular profiling of papillary thyroid carcinoma in Korea with a high prevalence of BRAFV600E mutation. Thyroid 201727 802-810. (https://doi.org/10.1089/thy.2016.0547)

20 Cho U, Mete O, Kim MH, Bae JS \& Jung CK. Molecular correlates and rate of lymph node metastasis of non-invasive follicular thyroid neoplasm with papillary-like nuclear features and invasive follicular variant papillary thyroid carcinoma: the impact of rigid criteria to distinguish non-invasive follicular thyroid neoplasm with papillarylike nuclear features. Modern Pathology 201730 810-825. (https://doi. org/10.1038/modpathol.2017.9)

21 Seo JY, Park JH, Pyo JY, Cha YJ, Jung CK, Song DE, Kwak JJ, Park SY, $\mathrm{Na}$ HY, Kim JH, et al. A multi-institutional study of prevalence and clinicopathologic features of non-invasive follicular thyroid neoplasm with papillary-like nuclear features (NIFTP) in Korea.
Journal of Pathology and Translational Medicine 201953 378-385. (https://doi.org/10.4132/jptm.2019.09.18)

22 Bychkov A, Jung CK, Liu Z \& Kakudo K. Noninvasive follicular thyroid neoplasm with papillary-like nuclear features in Asian practice: perspectives for surgical pathology and cytopathology. Endocrine Pathology 201829 276-288. (https://doi.org/10.1007/ s12022-018-9519-6)

23 Song YS, Lim JA \& Park YJ. Mutation profile of well-differentiated thyroid cancer in Asians. Endocrinology and Metabolism 201530 252-262. (https://doi.org/10.3803/EnM.2015.30.3.252)

24 Hirokawa M, Carney JA, Goellner JR, DeLellis RA, Heffess CS, Katoh R, Tsujimoto M \& Kakudo K. Observer variation of encapsulated follicular lesions of the thyroid gland. American Journal of Surgical Pathology 200226 1508-1514. (https://doi. org/10.1097/00000478-200211000-00014)

25 Kakudo K, Higuchi M, Hirokawa M, Satoh S, Jung CK \& Bychkov A. Thyroid FNA cytology in Asian practice-active surveillance for indeterminate thyroid nodules reduces overtreatment of thyroid carcinomas. Cytopathology 201728 455-466. (https://doi. org/10.1111/cyt.12491)

26 Ruanpeng D, Cheungpasitporn W, Thongprayoon C, Hennessey JV \& Shrestha RT. Systematic review and meta-analysis of the impact of noninvasive follicular thyroid neoplasm with papillary-like nuclear features (NIFTP) on cytological diagnosis and thyroid cancer prevalence. Endocrine Pathology 201930 189-200. (https://doi. org/10.1007/s12022-019-09583-4)

27 Brandler TC, Yee J, Zhou F, Cho M, Cangiarella J, Wei XJ, YeeChang M \& Sun W. Does noninvasive follicular thyroid neoplasm with papillary-like nuclear features have distinctive features on sonography? Diagnostic Cytopathology 201846 139-147. (https://doi. org/10.1002/dc.23863)

28 Johnson DN, Furtado LV, Long BC, Zhen CJ, Wurst M, Mujacic I, Kadri S, Segal JP, Antic T \& Cipriani NA. Noninvasive follicular thyroid neoplasms with papillary-like nuclear features are genetically and biologically similar to adenomatous nodules and distinct from papillary thyroid carcinomas with extensive follicular growth. Archives of Pathology and Laboratory Medicine 2018142 838-850. (https://doi.org/10.5858/arpa.2017-0118-OA)

29 Kim M, Jeon MJ, Oh HS, Park S, Kim TY, Shong YK, Kim WB, Kim K, Kim WG \& Song DE. BRAF and RAS mutational status in noninvasive follicular thyroid neoplasm with papillary-like nuclear features and invasive subtype of encapsulated follicular variant of papillary thyroid carcinoma in Korea. Thyroid 201828 504-510. (https://doi. org/10.1089/thy.2017.0382)

30 Song YS, Won JK, Yoo SK, Jung KC, Kim MJ, Kim SJ, Cho SW, Lee KE, Yi KH, Seo JS, et al. Comprehensive transcriptomic and genomic profiling of subtypes of follicular variant of papillary thyroid carcinoma. Thyroid 201828 1468-1478. (https://doi.org/10.1089/ thy.2018.0198)

31 Giannini R, Ugolini C, Poma AM, Urpì M, Niccoli C, Elisei R, Chiarugi M, Vitti P, Miccoli P \& Basolo F. Identification of two distinct molecular subtypes of non-invasive follicular neoplasm with papillary-like nuclear features by digital RNA counting. Thyroid 2017 27 1267-1276. (https://doi.org/10.1089/thy.2016.0605)

32 Lastra RR, Birdsong G, Hwang DH, Jorda M, Kerr DA, McGrath C, Odronic S, Rao R, VanderLaan PA, Walker JW, et al. Preoperative cytologic interpretation of noninvasive follicular thyroid neoplasm with papillary-like nuclear features: a 1-year multi-institutional experience. Journal of the American Society of Cytopathology 20187 79-85. (https://doi.org/10.1016/j.jasc.2017.12.004)

33 Zhao L, Dias-Santagata D, Sadow PM \& Faquin WC. Cytological, molecular, and clinical features of noninvasive follicular thyroid neoplasm with papillary-like nuclear features versus invasive forms of follicular variant of papillary thyroid carcinoma. Cancer Cytopathology 2017125 323-331. (https://doi.org/10.1002/ cncy.21839) 
34 Jiang XS, Harrison GP \& Datto MB. Young Investigator Challenge: molecular testing in noninvasive follicular thyroid neoplasm with papillary-like nuclear features. Cancer Cytopathology 2016124 893-900. (https://doi.org/10.1002/cncy.21802)

35 Nikiforov YE, Baloch ZW, Hodak SP, Giordano TJ, Lloyd RV, Seethala RR \& Wenig BM. Change in diagnostic criteria for noninvasive follicular thyroid neoplasm with papillarylike nuclear features. JAMA Oncology 20184 1125-1126. (https://doi.org/10.1001/ jamaoncol.2018.1446)

36 Seethala RR, Baloch ZW, Barletta JA, Khanafshar E, Mete O, Sadow PM, LiVolsi VA, Nikiforov YE, Tallini G \& Thompson LD. Noninvasive follicular thyroid neoplasm with papillary-like nuclear features: a review for pathologists. Modern Pathology 201831 39-55. (https://doi.org/10.1038/modpathol.2017.130)

37 Oh HS, Kim SJ, Song E, Lee YM, Sung TY, Kim WG, Kim TY \& Song DE. Modified transverse-vertical gross examination: a better method for the detection of definite capsular invasion in encapsulated follicular-patterned thyroid neoplasms. Endocrine Pathology 201930 106-112. (https://doi.org/10.1007/s12022-0199565-8)

38 Kim MJ, Won JK, Jung KC, Kim JH, Cho SW, Park DJ \& Park YJ. Clinical characteristics of subtypes of follicular variant papillary thyroid carcinoma. Thyroid 201828 311-318. (https://doi. org/10.1089/thy.2016.0671)

39 Ferris RL, Nikiforov Y, Terris D, Seethala RR, Ridge JA, Angelos P, Duh QY, Wong R, Sabra MM, Fagin JA, et al. AHNS Series: do you know your guidelines? AHNS Endocrine Section Consensus Statement: state-of-the-art thyroid surgical recommendations in the era of noninvasive follicular thyroid neoplasm with papillary-like nuclear features. Head and Neck 201840 1881-1888. (https://doi. org/10.1002/hed.25141)

40 Canini V, Leni D, Pincelli AI, Scardilli M, Garancini M, Villa C, Di Bella C, Capitoli G, Cimini R, Leone BE, et al. Clinical-pathological issues in thyroid pathology: study on the routine application of NIFTP diagnostic criteria. Scientific Reports 20199 13179. (https://doi. org/10.1038/s41598-019-49851-1)

41 Song SJ, LiVolsi VA, Montone K \& Baloch Z. Pre-operative features of non-invasive follicular thyroid neoplasms with papillary-like nuclear features: an analysis of their cytological, gene expression classifier and sonographic findings. Cytopathology 201728 488-494. (https:// doi.org/10.1111/cyt.12501)

42 Thompson LD. Ninety-four cases of encapsulated follicular variant of papillary thyroid carcinoma: a name change to noninvasive follicular thyroid neoplasm with papillary-like nuclear features would help prevent overtreatment. Modern Pathology 201629 698-707. (https:// doi.org/10.1038/modpathol.2016.65)

43 Yang GCH \& Fried KO. Pathologic basis of the sonographic differences between thyroid cancer and noninvasive follicular thyroid neoplasm with papillary-like nuclear features. Ultrasonography 201837 157-163. (https://doi.org/10.14366/ usg.17045)

44 You SH, Lee KE, Yoo RE, Choi HJ, Jung KC, Won JK, Kang KM, Yoon TJ, Choi SH, Sohn CH, et al. Prevention of total thyroidectomy in noninvasive follicular thyroid neoplasm with papillary-like nuclear features (NIFTP) based on combined interpretation of ultrasonographic and cytopathologic results. Clinical Endocrinology 201888 114-122. (https://doi.org/10.1111/cen.13473)

45 Yang GCH, Fried KO \& Scognamiglio T. Sonographic and cytologic differences of NIFTP from infiltrative or invasive encapsulated follicular variant of papillary thyroid carcinoma: a review of 179 cases. Diagnostic Cytopathology 201745 533-541. (https://doi. org/10.1002/dc.23709)

46 Lam CA, McGettigan MJ, Thompson ZJ, Khazai L, Chung CH, Centeno BA, McIver B \& Valderrabano P. Ultrasound characterization for thyroid nodules with indeterminate cytology: inter-observer agreement and impact of combining pattern-based and scoring-based classifications in risk stratification. Endocrine 201966 278-287. (https://doi.org/10.1007/s12020-019-02000-0)

47 Choi SH, Kim EK, Kwak JY, Kim MJ \& Son EJ. Interobserver and intraobserver variations in ultrasound assessment of thyroid nodules. Thyroid 201020 167-172. (https://doi.org/10.1089/thy.2008.0354)

48 Park SH, Kim SJ, Kim EK, Kim MJ, Son EJ \& Kwak JY. Interobserver agreement in assessing the sonographic and elastographic features of malignant thyroid nodules. American Journal of Roentgenology 2009 193 W416-W423. (https://doi.org/10.2214/AJR.09.2541)

49 Rosario PW. Is Doppler ultrasonography of value for the differentiation between noninvasive follicular thyroid neoplasm with papillary-like nuclear features (NIFTP) and invasive encapsulated follicular variant of papillary thyroid carcinoma? Clinical Endocrinology 201888 506-507. (https://doi.org/10.1111/ cen.13523)

50 Rosario PW, Mourão GF, Nunes MB, Nunes MS \& Calsolari MR. Noninvasive follicular thyroid neoplasm with papillary-like nuclear features. Endocrine-Related Cancer 201623 893-897. (https://doi. org/10.1530/ERC-16-0379)

51 Hahn SY, Shin JH, Oh YL, Kim TH, Lim Y \& Choi JS. Role of ultrasound in predicting tumor invasiveness in follicular variant of papillary thyroid carcinoma. Thyroid 201727 1177-1184. (https:// doi.org/10.1089/thy.2016.0677)

52 Rosario PW, da Silva AL, Nunes MB \& Borges MAR. Risk of malignancy in thyroid nodules using the American College of Radiology thyroid imaging reporting and data system in the NIFTP era. Hormone and Metabolic Research 201850 735-737. (https://doi. org/10.1055/a-0743-7326)

53 Rosario PW, Silva TH \& de Oliveira PHL. Impact of noninvasive follicular thyroid neoplasm with papillary-like nuclear features (NIFTP) on the risk of malignancy estimated by the ultrasonographic classification of the American Thyroid Association (ATA) in thyroid nodules $>1$ cm. Endocrine 201860 535-536. (https://doi.org/10.1007/ s12020-018-1585-5)

54 Cibas ES \& Ali SZ. The 2017 Bethesda system for reporting thyroid cytopathology. Thyroid 201727 1341-1346. (https://doi.org/10.1089/ thy.2017.0500)

55 Krane JF, Alexander EK, Cibas ES \& Barletta JA. Coming to terms with NIFTP: a provisional approach for cytologists. Cancer Cytopathology 2016124 767-772. (https://doi.org/10.1002/cncy.21769)

56 Zhang Z, Chhieng D, Harshan M, Zheng X \& Zakowski M. Cytological features of noninvasive follicular thyroid neoplasm with papillary-like nuclear features (NIFTP). Journal of the American Society of Cytopathology 20198 5-10. (https://doi.org/10.1016/j. jasc.2018.07.007)

57 Brandler TC, Zhou F, Liu CZ, Cho M, Lau RP, Simsir A, Patel KN \& Sun W. Can noninvasive follicular thyroid neoplasm with papillarylike nuclear features be distinguished from classic papillary thyroid carcinoma and follicular adenomas by fine-needle aspiration? Cancer Cytopathology 2017125 378-388. (https://doi.org/10.1002/ cncy.21848)

58 Maletta F, Massa F, Torregrossa L, Duregon E, Casadei GP, Basolo F, Tallini G, Volante M, Nikiforov YE \& Papotti M. Cytological features of 'noninvasive follicular thyroid neoplasm with papillarylike nuclear features' and their correlation with tumor histology. Human Pathology 201654 134-142. (https://doi.org/10.1016/j. humpath.2016.03.014)

59 Bongiovanni M, Giovanella L, Romanelli F \& Trimboli P. Cytological diagnoses associated with noninvasive follicular thyroid neoplasms with papillary-like nuclear features according to the Bethesda system for reporting thyroid cytopathology: a systematic review and meta-analysis. Thyroid 201929 222-228. (https://doi.org/10.1089/ thy.2018.0394)

60 Guleria P, Agarwal S, Iyer VK, Jain D, Mathur SR \& Yadav D. Subcategorisation of AUS/FLUS thyroid lesions as per the 2017 Bethesda System for Reporting Thyroid Cytopathology: 
a retrospective study from a tertiary care centre analysing risk of malignancy (ROM) of the different subcategories. Journal of Clinical Pathology 201972 771-777. (https://doi.org/10.1136/ jclinpath-2019-205985)

61 Canberk S, Gunes P, Onenerk M, Erkan M, Kilinc E, Kocak Gursan N \& Kilicoglu GZ. New concept of the encapsulated follicular variant of papillary thyroid carcinoma and its impact on the Bethesda system for reporting thyroid cytopathology: a singleinstitute experience. Acta Cytologica 201660 198-204. (https://doi. org/10.1159/000447990)

62 Faquin WC, Wong LQ, Afrogheh AH, Ali SZ, Bishop JA, Bongiovanni M, Pusztaszeri MP, VandenBussche CJ, Gourmaud J, Vaickus LJ, et al. Impact of reclassifying noninvasive follicular variant of papillary thyroid carcinoma on the risk of malignancy in the Bethesda System for Reporting Thyroid Cytopathology. Cancer Cytopathology 2016124 181-187. (https://doi.org/10.1002/ cncy.21631)

63 Kiernan CM, Weiss VL, Mehrad M, Ely K, Baregamian N \& Solórzano CC. New terminology-noninvasive follicular neoplasm with papillary-like nuclear features (NIFTP) and its effect on the rate of malignancy at a single institution. Surgery 2018163 55-59. (https://doi.org/10.1016/j.surg.2017.04.041)

64 Kim M, Kim JE, Kim HJ, Chung YR, Kwak Y \& Park SY. Cytologic diagnosis of noninvasive follicular thyroid neoplasm with papillary-like nuclear features and its impact on the risk of malignancy in the Bethesda system for reporting thyroid cytopathology: an institutional experience. Journal of Pathology and Translational Medicine 201852 171-178. (https://doi.org/10.4132/ jptm.2018.04.03)

65 Lau RP, Paulsen JD, Brandler TC, Liu CZ, Simsir A \& Zhou F. Impact of the reclassification of 'noninvasive encapsulated follicular variant of papillary thyroid carcinoma' to 'noninvasive follicular thyroid neoplasm With papillary-like nuclear features' on the Bethesda system for reporting thyroid cytopathology: a large academic institution's experience. American Journal of Clinical Pathology 2017 149 50-54. (https://doi.org/10.1093/ajcp/aqx136)

66 Layfield LJ, Baloch ZW, Esebua M, Kannuswamy R \& Schmidt RL. Impact of the reclassification of the non-invasive follicular variant of papillary carcinoma as benign on the malignancy risk of the Bethesda system for reporting thyroid cytopathology: a metaanalysis study. Acta Cytologica 201761 187-193. (https://doi. org/10.1159/000469654)

67 Lindeman BM, Nehs MA, Angell TE, Alexander EK, Gawande AA, Moore FD, Doherty GM \& Cho NL. Effect of noninvasive follicular thyroid neoplasm with papillary-like nuclear features (NIFTP) on malignancy rates in thyroid nodules: how to counsel patients on extent of surgery. Annals of Surgical Oncology 201926 93-97. (https:// doi.org/10.1245/s10434-018-6932-5)

68 Sung S, Margolskee E, Chen D \& Tiscornia-Wasserman P. Incidence of noninvasive follicular thyroid neoplasm with papillary-like nuclear features and change in risk of malignancy for 'the Bethesda System for Reporting Thyroid Cytology.' Journal of the American Society of Cytopathology 20198 133-140. (https://doi.org/10.1016/j. jasc.2019.01.005)

69 Ventura M, Melo M, Fernandes G \& Carrilho F. Risk of malignancy in thyroid cytology: the impact of the reclassification of noninvasive follicular thyroid neoplasm with papillary-like nuclear features (NIFTP). Endocrine Practice 201925 642-647. (https://doi. org/10.4158/EP-2018-0423)

70 Zhou H, Baloch ZW, Nayar R, Bizzarro T, Fadda G, AdhikariGuragain D, Hatem J, Larocca LM, Samolczyk J, Slade J, et al. Noninvasive follicular thyroid neoplasm with papillary-like nuclear features (NIFTP): implications for the risk of malignancy (ROM) in the Bethesda System for Reporting Thyroid Cytopathology (TBSRTC). Cancer Cytopathology 2018126 20-26. (https://doi.org/10.1002/ cncy.21926)
71 Vuong HG, Tran TTK, Bychkov A, Jung CK, Nakazawa T, Kakudo K, Katoh R \& Kondo T. Clinical impact of non-invasive follicular thyroid neoplasm with papillary-like nuclear features on the risk of malignancy in the Bethesda system for reporting thyroid cytopathology: a meta-analysis of 14,153 resected thyroid nodules. Endocrine Practice 201925 491-502. (https://doi.org/10.4158/ EP-2018-0506)

72 Bychkov A, Keelawat S, Agarwal S, Jain D, Jung CK, Hong S, Lai CR, Satoh S \& Kakudo K. Impact of non-invasive follicular thyroid neoplasm with papillary-like nuclear features on the Bethesda system for reporting thyroid cytopathology: a multi-institutional study in five Asian countries. Pathology 201850 411-417. (https://doi. org/10.1016/j.pathol.2017.11.088)

73 Bongiovanni M, Faquin WC, Giovanella L, Durante C, Kopp P \& Trimboli P. Impact of non-invasive follicular thyroid neoplasms with papillary-like nuclear features (NIFTP) on risk of malignancy in patients undergoing lobectomy/thyroidectomy for suspicious for malignancy or malignant fine-needle aspiration cytology findings: a systematic review and meta-analysis. European Journal of Endocrinology 2019181 389-396. (https://doi.org/10.1530/EJE-19-0223)

74 Strickland KC, Vivero M, Jo VY, Lowe AC, Hollowell M, Qian X, Wieczorek TJ, French CA, Teot LA, Sadow PM, et al. Preoperative cytologic diagnosis of noninvasive follicular thyroid neoplasm with papillary-like nuclear features: a prospective analysis. Thyroid 2016 26 1466-1471. (https://doi.org/10.1089/thy.2016.0280)

75 Legesse T, Parker L, Heath J \& Staats PN. Distinguishing non-invasive follicular thyroid neoplasm with papillary-like nuclear features (NIFTP) from classic and invasive follicular-variant papillary thyroid carcinomas based on cytologic features. Journal of the American Society of Cytopathology 20198 11-17. (https://doi.org/10.1016/j. jasc.2018.07.004)

76 Koshikawa T, Fujita N, Ueda N, Ota Y, Sasaki E, Murakami Y, Hosoda W, Yatabe Y, Hanai N, Higuchi M, et al. Important cytological findings for distinction between follicular variant and conventional papillary thyroid carcinoma, including noninvasive follicular thyroid tumors with papillary-like nuclear features. Endocrine Journal 201966 475-483. (https://doi.org/10.1507/endocrj.EJ18-0525)

77 Strickland KC, Eszlinger M, Paschke R, Angell TE, Alexander EK, Marqusee E, Nehs MA, Jo VY, Lowe A, Vivero M, et al. Molecular testing of nodules with a suspicious or malignant cytologic diagnosis in the setting of non-invasive follicular thyroid neoplasm with papillary-like nuclear features (NIFTP). Endocrine Pathology 201829 68-74. (https://doi.org/10.1007/s12022-018-9515-x)

78 Bizzarro T, Martini M, Capodimonti S, Straccia P, Lombardi CP, Pontecorvi A, Larocca LM \& Rossi ED. Young investigator challenge: the morphologic analysis of noninvasive follicular thyroid neoplasm with papillary-like nuclear features on liquid-based cytology: some insights into their identification. Cancer Cytopathology 2016124 699-710. (https://doi.org/10.1002/cncy.21777)

79 Strickland KC, Howitt BE, Barletta JA, Cibas ES \& Krane JF. Suggesting the cytologic diagnosis of noninvasive follicular thyroid neoplasm with papillary-like nuclear features (NIFTP): a retrospective analysis of atypical and suspicious nodules. Cancer Cytopathology 2018126 86-93. (https://doi.org/10.1002/cncy.21922)

80 Kwon H, Jeon MJ, Yoon JH, Hong SJ, Lee JH, Kim TY, Shong YK, Kim WB, Kim WG \& Song DE. Preoperative clinicopathological characteristics of patients with solitary encapsulated follicular variants of papillary thyroid carcinomas. Journal of Surgical Oncology 2017116 746-755. (https://doi.org/10.1002/jso.24700)

81 Kwon MR, Shin JH, Hahn SY, Oh YL, Kwak JY, Lee E \& Lim Y. Histogram analysis of greyscale sonograms to differentiate between the subtypes of follicular variant of papillary thyroid cancer. Clinical Radiology 201873 591.e1-591.e7. (https://doi.org/10.1016/j. crad.2017.12.008)

82 Hahn SY, Shin JH, Lim HK, Jung SL, Oh YL, Choi IH \& Jung CK. Preoperative differentiation between noninvasive follicular 
thyroid neoplasm with papillary-like nuclear features (NIFTP) and non-NIFTP. Clinical Endocrinology 201786 444-450. (https://doi. org/10.1111/cen.13263)

83 Lee HS, Lee JW, Park JH, Kim WS, Han HS \& Lee SE. Comprehensive analysis for diagnosis of preoperative non-invasive follicular thyroid neoplasm with papillary-like nuclear features. PLOS ONE 201914 e0218046. (https://doi.org/10.1371/journal.pone.0218046)

84 Díaz Del Arco C \& Fernández Aceñero MJ. Noninvasive follicular thyroid neoplasm with papillary-like nuclear features: can cytology face the challenge of diagnosis in the light of the new classification? Acta Cytologica 201862 265-272. (https://doi. org/10.1159/000488579)

85 Sohn SY, Lee JJ \& Lee JH. Molecular profile and clinicopathologic features of follicular variant papillary thyroid carcinoma. Pathology Oncology Research 2019 [epub]. (https://doi.org/10.1007/s12253-01900639-8)

$86 \mathrm{Xu} \mathrm{B}$, Tuttle RM, Sabra MM, Ganly I \& Ghossein R. Primary thyroid carcinoma with low-risk histology and distant metastases: clinicopathologic and molecular characteristics. Thyroid 201727 632-640. (https://doi.org/10.1089/thy.2016.0582)

87 Proietti A, Sartori C, Macerola E, Borrelli N, Materazzi G, Vitti P \& Basolo F. Low frequency of tert promoter mutations in a series of welldifferentiated follicular-patterned thyroid neoplasms. Virchows Archiv 2017471 769-773. (https://doi.org/10.1007/s00428-017-2236-6)

88 Jug RC, Datto MB \& Jiang XS. Molecular testing for indeterminate thyroid nodules: performance of the Afirma gene expression classifier and ThyroSeq panel. Cancer Cytopathology 2018126 471-480. (https://doi.org/10.1002/cncy.21993)

89 Steward DL, Carty SE, Sippel RS, Yang SP, Sosa JA, Sipos JA, Figge JJ, Mandel S, Haugen BR, Burman KD, et al. Performance of a multigene genomic classifier in thyroid nodules with indeterminate cytology: a prospective blinded multicenter study. JAMA Oncology 20195 204-212. (https://doi.org/10.1001/jamaoncol.2018.4616)

90 Valderrabano P, Khazai L, Leon ME, Thompson ZJ, Ma Z, Chung CH, Hallanger-Johnson JE, Otto KJ, Rogers KD, Centeno BA, et al. Evaluation of ThyroSeq v2 performance in thyroid nodules with indeterminate cytology. Endocrine-Related Cancer 201724 127-136. (https://doi.org/10.1530/ERC-16-0512)

91 Sowder AM, Witt BL \& Hunt JP. An update on the risk of lymph node metastasis for the follicular variant of papillary thyroid carcinoma with the new diagnostic paradigm. Head and Neck Pathology 201812 105-109. (https://doi.org/10.1007/s12105-017-0835-9)

92 Paniza ACJ, Mendes TB, Vianna MDB, Thomaz DMD, Chiappini PBO, Colazza-Gama GA, Lindsey SC, de Carvalho MB, Alves VAF, Curione $\mathrm{O}$, et al. Revised criteria for diagnosis of NIFTP reveals a better correlation with tumor biological behavior. Endocrine Connections 20198 1529-1538. (https://doi.org/10.1530/EC-19-0459)

$93 \mathrm{Xu} \mathrm{B}$, Tallini G, Scognamiglio T, Roman BR, Tuttle RM \& Ghossein RA. Outcome of large noninvasive follicular thyroid neoplasm with papillary-like nuclear features. Thyroid 201727 512-517. (https://doi.org/10.1089/thy.2016.0649)

94 Rosario PW. Long-term outcomes of patients with noninvasive follicular thyroid neoplasm with papillary-like nuclear features (NIFTP) $\geq 4 \mathrm{~cm}$ treated without radioactive iodine. Endocrine Pathology 201728 367-368. (https://doi.org/10.1007/s12022-017-9493-4)

95 Shafique K, LiVolsi VA, Montone K \& Baloch ZW. Papillary thyroid microcarcinoma: reclassification to non-invasive follicular thyroid neoplasm with papillary-like nuclear features (NIFTP): a retrospective clinicopathologic study. Endocrine Pathology 201829 339-345. (https://doi.org/10.1007/s12022-018-9546-3)

$96 \mathrm{Xu} \mathrm{B}$, Farhat N, Barletta JA, Hung YP, de Biase D, Casadei GP Onenerk AM, Tuttle RM, Roman BR, Katabi N, et al. Should subcentimeter non-invasive encapsulated, follicular variant of papillary thyroid carcinoma be included in the noninvasive follicular thyroid neoplasm with papillary-like nuclear features category? Endocrine 201859 143-150. (https://doi.org/10.1007/s12020-0171484-1)

97 Rosario PW, Mourão GF, Oliveira LFF \& Calsolari MR. Long-term follow-up in patients with noninvasive follicular thyroid neoplasm with papillary-like nuclear features (NIFTP) without a suspicion of persistent disease in postoperative assessment. Hormone and Metabolic Research 201850 223-226. (https://doi.org/10.1055/s-0043-121707)

Received in final form 2 February 2020

Accepted 12 February 2020

Accepted Manuscript published online 12 February 2020 https://ec.bioscientifica.com https://doi.org/10.1530/EC-19-0566 (c) 2020 The authors Published by Bioscientifica Ltd
This work is licensed under a Creative Commons Attribution-NonCommercial-NoDerivatives 4.0 Internationab sicense.ifica . com at 04/26/2023 01:53:19PM 